\title{
Nonlinear Analysis of Cable Vibration of a Multispan Cable-Stayed Bridge under Transverse Excitation
}

\author{
Kun Lin, ${ }^{1}$ Dujian Zou, ${ }^{2}$ and Minghai $\mathrm{Wei}^{3}$ \\ ${ }^{1}$ Shenzhen Graduate School, Harbin Institute of Technology, Shenzhen 518055, China \\ ${ }^{2}$ Graduate School at Shenzhen, Tsinghua University, Shenzhen 518055, China \\ ${ }^{3}$ Department of Construction and Engineering Management, Shenyang Jianzhu University, Shenyang 110168, China
}

Correspondence should be addressed to Dujian Zou; zoudujian@163.com

Received 30 October 2013; Revised 26 December 2013; Accepted 26 December 2013; Published 10 February 2014

Academic Editor: Hamid Reza Karimi

Copyright (c) 2014 Kun Lin et al. This is an open access article distributed under the Creative Commons Attribution License, which permits unrestricted use, distribution, and reproduction in any medium, provided the original work is properly cited.

\begin{abstract}
The nonlinear vibrations of cable in a multispan cable-stayed bridge subjected to transverse excitation are investigated. The MECS (multielements cable system) model, where multielements per cable stay are used, is built up and used to analyze the model properties of the multispan cable-stayed bridges. Then, a simplified two-degrees-of-freedom (2-DOFs) model, where the tower or the deck is reduced to a beam, is proposed to analyze the nonlinear dynamic behaviors of the beam and cable. The results of MECS model analysis show that the main tower in the multispan cable-stayed bridge is prone to the transverse vibration, and the local vibration of cables only has a little impact on the frequency values of the global modes. The results of simplified model analysis show that the energy can be transformed between the modes of the beam and cable when the nature frequencies of them are very close. On the other hand, with the transverse excitation changing, the cable can exhibit richer quasi-periodic or chaotic motions due to the nonlinear terms caused by the coupled mode between the beam and cable.
\end{abstract}

\section{Introduction}

Recently, as use of multispan cable-stayed bridges increases continuously, the real local vibration features of inclined cables and coupled oscillation characteristics between the cable and the bridge is becoming a new topic in the design process. The stabilization of the central towers under extreme wind or seismic vibration is a key issue, since they cannot be anchored to an outer fixed support. One solution is to use the stabilizing cables which run from the top of the central towers to a location on the deck near the side towers, such as the Ting-Kau Bridge in Hong Kong. Another solution is to increase the stiffness of the central towers itself, and most multispan cable-stayed bridges adopt this way, such as the Maracaibo Bridge in Venezuela, the Millau Bridge in France, the Mezcala Bridge in Mexico, the Dong-Ting Lake Bridge, the Yi-Ling Bridge, and the Bin-Zhou Bridge in China.

$\mathrm{Ni}$ et al. [1] investigated the effect of stabilizing cables on the seismic response of Ting Kau Bridge based on a validated 3D finite-element model. He et al. [2] investigated the influences of cable local modes and stabilizing cables for the Dong-Ting Lake Bridge on seismic excitation. Liu [3] investigated the seismic performance of rigid system, floating system, and passive energy dissipation system for the Bin-Zhou Bridge under two different earthquake records. In order to evaluate the stability of the main towers of Millau Bridge, Okamoto and Nakamura [4] proposed a new hybrid high tower and investigated their static and seismic behaviors. Most of the above studies focused on the stabilization of central towers, and little attention has been devoted to investigating the effects of cable vibration on the properties of tower or deck under transverse excitation.

On the other hand, all the above researchers used the finite-element (FE) model to investigate the stabilization of towers by taking the specific project as a paradigm. From the perspective of the coupled vibration between cable and tower (or deck), Fujino et al. [5] presented a 3-DOFs analytical model to investigate the auto-parametric interaction 
behavior of cable and beam structure, the case which under a random excitation is firstly studied by Xia et al. [6, 7]. The results show that the horizontal motions of the cable and beam are excited due to the autoparametric nonlinear coupling behavior under some cases. Caetano et al. [8, 9] studied the dynamic interactions between the cable and deck or tower in cable-stayed bridges by physical modelling and experimental testing. Georgakis and Taylor $[10,11]$ presented an alternative cable-deck model to investigate the nonlinear dynamics of an inclined cable which both induced by sinusoidal and stochastic support excitations. The different cabledeck interactions of the Guadiana Bridge under environmental excitations were investigated by Caetano et al. [12], using the vibration data acquisitions and a refined finite element model. However, few studies focus on the nonlinear vibration of the cable-tower (or beam) coupled system subjected to transverse excitation.

The objective of this paper is to study the nonlinear vibrations of cable in a multispan cable-stayed bridge subjected to transverse excitation. Taking the Bin-Zhou cable-stayed bridge (BZB) as a paradigm, the MECS model, where multielements per cable stay are used, is firstly built up and used to investigate the effects of the cable's vibration on the properties of the BZB. Then, the possibility of the transverse resonance between the local model (cable) and global model (tower or deck) is analyzed. Based on the results of the above studies, a simplified 2-DOFs model, where the tower or the deck is reduced to a tower (or beam), is proposed to analyze the nonlinear coupled vibration of the cable and tower (or beam). The coupled relationship is completely from the dynamic interactions between the cable and tower (or beam). After that, the equations of motion are solved by using Galerkin's method for the spatial problems and the method of multiple time scales for temporal problems. The stability of the steadystate solution is examined. Finally, the nonlinear behavior of the cable and tower (or beam) is analyzed by using the time histories, phase portraits, and Poincare maps with the transverse excitation changing.

\section{Vibration Properties of the Multispan Cable-Stayed Bridge}

2.1. Outline of the Bin-Zhou Cable-Stayed Bridge. The BZB, as shown in Figure 1, is a three-tower cable-stayed bridge with two main spans of $300 \mathrm{~m}$ and two-side spans of $84 \mathrm{~m}$ each. The bridge deck is separated into two carriageways with a width of $13.75 \mathrm{~m}$ each. There are two minor towers with heights of $75.78 \mathrm{~m}$ in both sides and a main tower with a height of $125.28 \mathrm{~m}$ in the center. It has a unique feature that there is no horizontal component connecting the towers. The carriageways consist of two longitudinal pre-stressed concrete box girders with a length of $767.1 \mathrm{~m}$ and a height of $3 \mathrm{~m}$. Along the deck edges, there are cross-girders at $7 \mathrm{~m}$ and $6 \mathrm{~m}$ intervals for the main span and two side spans, respectively. The locations of cables are consistent with the cross-girders. The bridge deck is fixed at main towers, but linked at the minor towers and two end abutments. There are 200 main stay cables anchored to the towers with intervals of
$2 \mathrm{~m}$ (partial $2.5 \mathrm{~m}$ ). Shown as Figure 1, from left to right the cables anchored to the left minor tower, the main tower and the right minor tower are named as A1 A12, N1 N26 and J1 J12 respectively.

The 3-D FE model of the BZB is established in ANSYS, as shown in Figure 2. The bridge members, girders, towers, and deck are simulated by spatial beam or shell elements with six DOFs at each node, respectively. In order to reflect the influence of cable vibration, the cables are simulated by spatial spar elements with 3-DOFs at each node; each cable is divided by a length of $6 \mathrm{~m}$. As a result, the FE model involves 7696 nodes and 7514 elements.

2.2. Modal Analysis. Based on the aforementioned criterions, the natural vibration frequencies and global modes are examined by using OECS (one-element cable system) and MECS models. The frequencies and mode shapes of the first 10 modes of OECS model and the first 300 modes of MESC model are computed. Among the latter ones, the maximum frequency is up to $1.598 \mathrm{~Hz}$, and over $85 \%$ of modes are pure cable local vibration modes. This property is similar to the Ting Kau Bridge $[1,13]$.

According to the same global mode shapes, Table 1 shows a comparison of the natural frequencies of the OECS and MESC models. From Table 1, the first mode of the BZB is predominantly vertical bending, which differs from most of the cable-stayed bridges. This phenomenon can be attributed to the semifloating system adopted in the BZB. The vibration frequencies of the first 10 global modes of MECS model have minor difference to the OECS model and have a max difference of $3.24 \%$ in 5 th mode and $-0.476 \%$ in 2 nd mode. Moreover, the increase in frequencies is related to the deck and the decrease is related to the towers. These results differ from the conclusion given by Wang et al. [14]. The tower modes also have a larger proportion in the first 10 global modes of the BZB, and most of them are the lateral vibrations, as seen in Figure 3. It may be explained by the fact that the lack of the horizontal component between the towers makes the overall performance of the BZB very poor in the transversal direction. Compared to the OECS model, as seen in Figure 3, the MECS model can offer all the vibration modes of the BZB including the global coupled modes and the local modes of cable stays.

2.3. Possibility of the Transverse Resonance between the Local Model and Global Model. Table 2 shows the relationship between the natural frequencies of the global modes and part of the cables in the BZB. It is seen that the transverse coupled vibration between the tower and cable due to the $1: 2$ or 1:1 internal resonance mechanism are possibly to occur. For example, the natural frequencies of cables N23, N24, N25, $\mathrm{N} 26$, and $\mathrm{N} 13, \mathrm{~N} 14, \mathrm{~N} 15$ are in the one times or two times vicinity of the natural frequency of the 2nd lateral bending mode, respectively. On the other hand, the minor tower and cables also occur the transverse coupled vibration, such as the 7 th, 8 th, 9th, and 10th lateral bending modes for the cables A9 and 88 . 

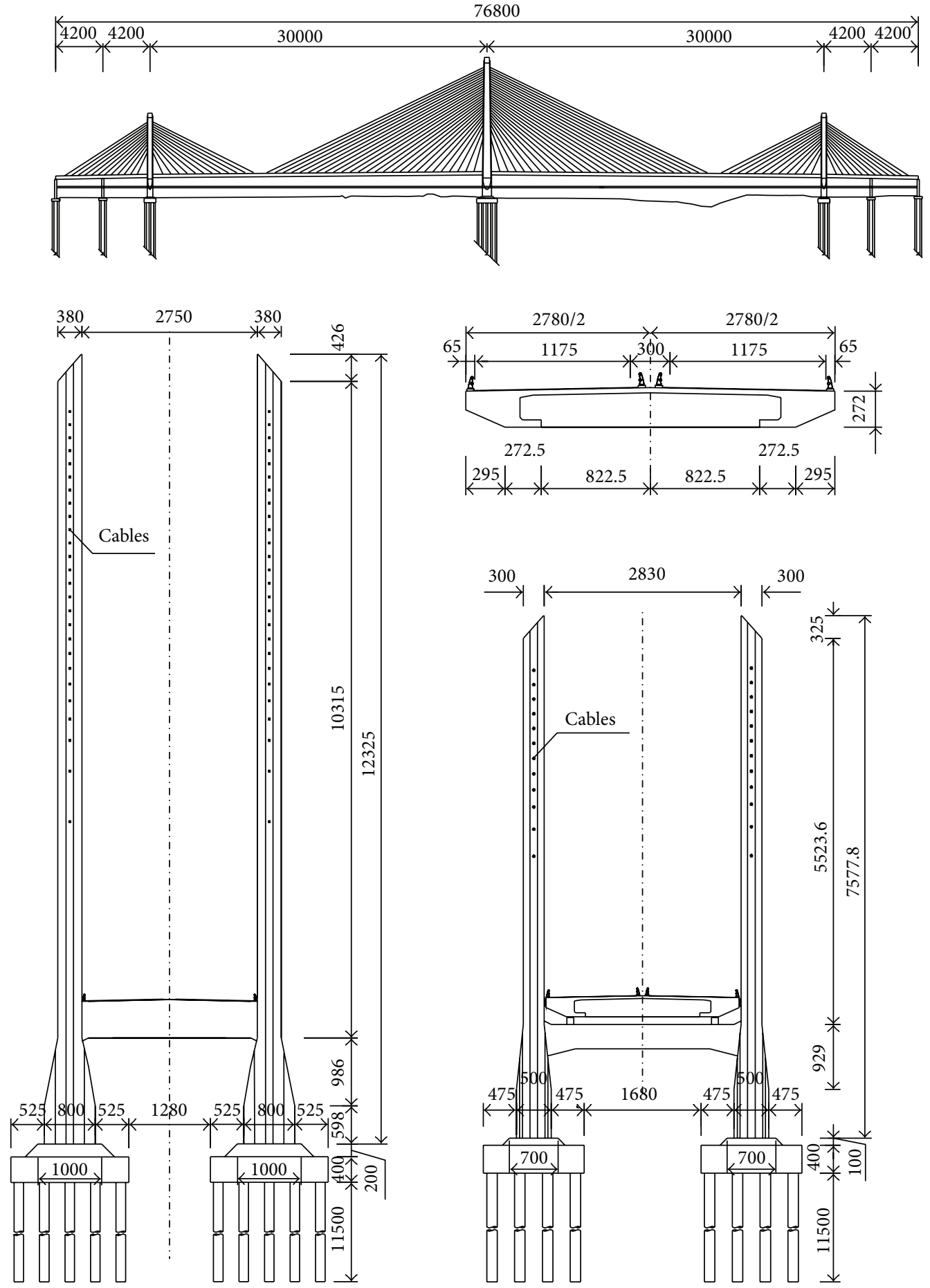

Figure 1: View of the Bin-Zhou Bridge $(\mathrm{cm})$.

\section{Simplified Model}

3.1. Equations of Motion. In this section, the coupled vibrations between the cable and tower of the BZB under transverse excitation have been investigated by a simplified
2-DOFs model, in which the tower is reduced to a beam. The simplified model consists of a beam and a cable, each of them fixed at one end and attached to the other end as considered in Figure 4. The beam is considered as an Euler-Bernoulli beam and the cable is simulated ignoring the bending, torsional, 


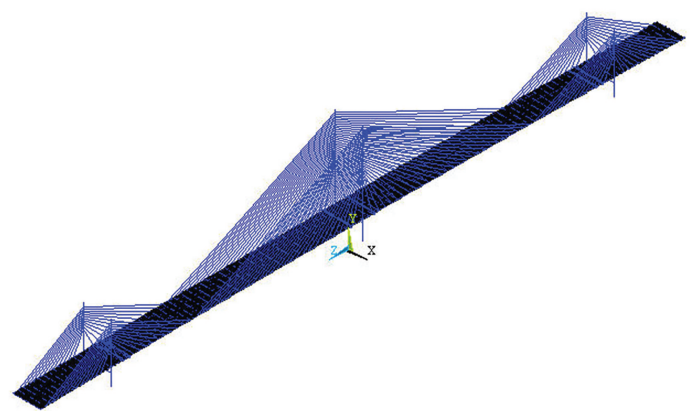

FIGURE 2: FE model of the Bin-Zhou Bridge.

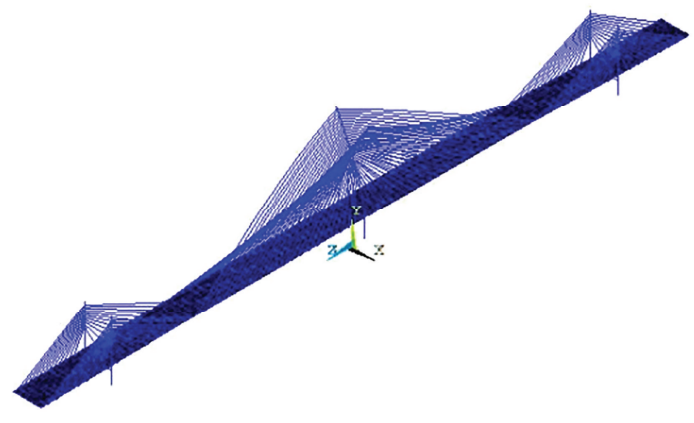

(a) The 2nd-order mode shape

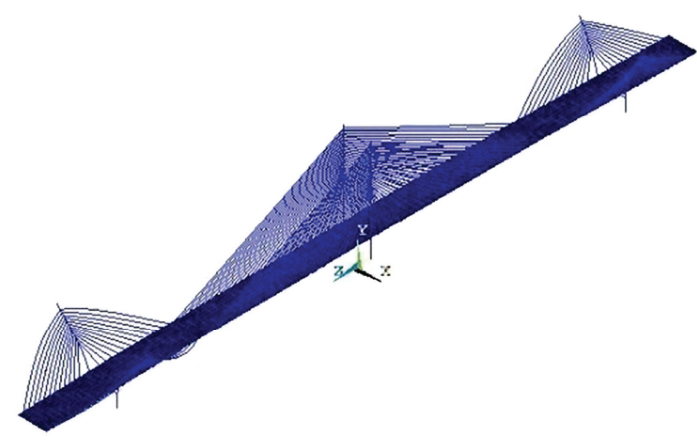

(c) The 57th-order mode shape

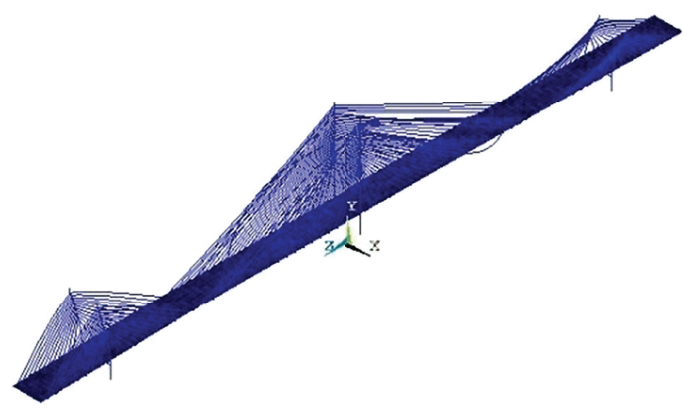

(b) The 42th-order mode shape

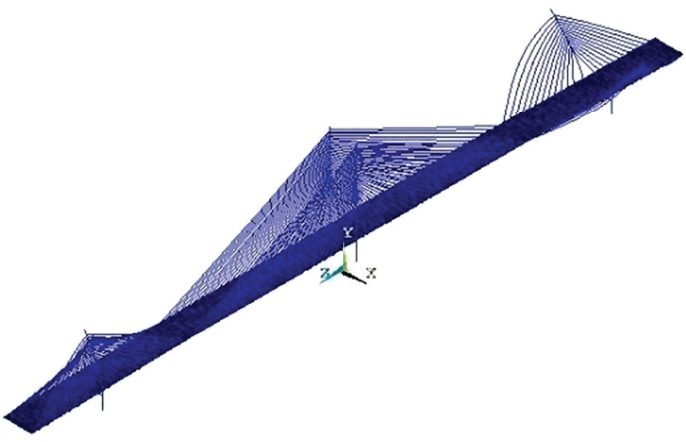

(d) The 69th-order mode shape

FIgURE 3: The lateral mode shapes of the MESC model.

TABLE 1: Comparison of natural frequencies for the first ten global modes.

\begin{tabular}{|c|c|c|c|c|}
\hline Mode order & OESC $(\mathrm{Hz})$ & $\operatorname{MESC}(\mathrm{Hz})$ & Structural component & Description (MESC) \\
\hline 1 & 0.2725 & 0.2756 & Deck & Antisymmetric vertical bending \\
\hline 2 & 0.2939 & 0.2925 & Main Tower & Lateral bending \\
\hline 3 & 0.2961 & 0.2947 & Main Tower & Longitudinal bending \\
\hline 4 & 0.4429 & 0.4470 & Deck & Torsional bending \\
\hline 5 & 0.5424 & 0.5600 & Deck & Symmetric vertical bending \\
\hline $6(41)$ & 0.6592 & 0.6686 & Deck & Antisymmetric vertical bending \\
\hline $7(42)$ & 0.6737 & 0.6714 & Minor tower 1,2 & Lateral + longitudinal bending \\
\hline $8(56)$ & 0.6748 & 0.6728 & Minor tower 1,2 & Longitudinal bending \\
\hline $9(57)$ & 0.6996 & 0.6972 & Minor tower 1,2 & Lateral bending \\
\hline $10(69)$ & 0.6996 & 0.6972 & Minor tower 1,2 & Longitudinal + lateral bending \\
\hline
\end{tabular}

Note. The numbers in brackets are the mode order of the MESC model. 


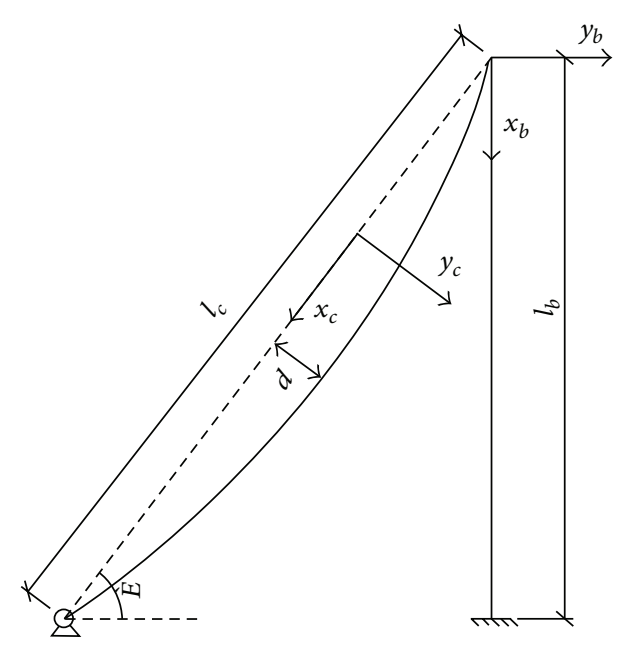

(a) Static model

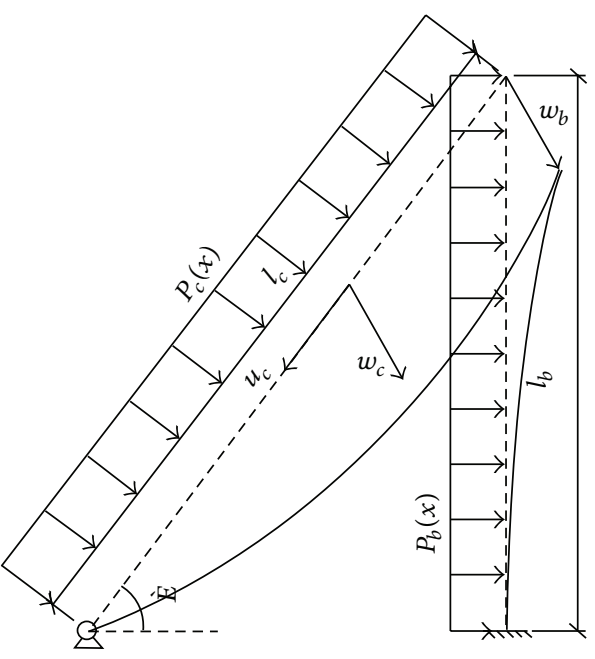

(b) Dynamic model

FIGURE 4: The simplified model.

TABLE 2: Cables which may take place of the transverse coupled vibration between the global mode and cable.

\begin{tabular}{|c|c|c|c|c|}
\hline Mode number (OECS) & Natural frequency $(\mathrm{Hz})$ & Cable number & Natural frequency $(\mathrm{Hz})$ & Ratio \\
\hline \multirow{7}{*}{ 2nd } & \multirow{7}{*}{0.2939} & $\mathrm{~N} 23$ & 0.313 & $0.939(1: 1)$ \\
\hline & & $\mathrm{N} 24$ & 0.310 & $0.948(1: 1)$ \\
\hline & & N25 & 0.289 & $1.017(1: 1)$ \\
\hline & & N26 & 0.271 & $1.085(1: 1)$ \\
\hline & & $\mathrm{N} 13$ & 0.648 & $0.454(1: 2)$ \\
\hline & & N14 & 0.554 & $0.531(1: 2)$ \\
\hline & & N15 & 0.536 & $0.548(1: 2)$ \\
\hline \multirow{2}{*}{ 7th, 8th } & \multirow{2}{*}{0.6737} & A9 & 1.392 & $0.484(1: 2)$ \\
\hline & & J8 & 1.373 & $0.491(1: 2)$ \\
\hline \multirow{2}{*}{ 9th, 10th } & \multirow{2}{*}{0.6996} & A9 & 1.392 & $0.503(1: 2)$ \\
\hline & & J8 & 1.373 & $0.510(1: 2)$ \\
\hline
\end{tabular}

and shear rigidities behavior. In addition, the beam and cable are assumed to be homogeneous and oscillate transversely only in outplane.

Considering the previous assumptions, the equations of motion for the simplified model are obtained by using the extended Hamilton principle:

$$
\begin{gathered}
m_{b} \ddot{w}_{b}+\xi_{b} \dot{w}_{b}+E_{b} I_{b} w_{b}^{\prime \prime \prime \prime}+N w_{b}^{\prime \prime}=P_{b} \cos \left(\Omega_{b} t\right), \\
m_{c} \ddot{w}_{c}+\xi_{c} \dot{w}_{c}-\left[H w_{c}^{\prime}+E_{c} A_{c} w_{c}^{\prime} e(t)\right]^{\prime}=P_{c} \cos \left(\Omega_{c} t\right), \\
N=\left(H+E_{c} A_{c} e(t)\right) \sin (\theta), \\
e(t)=\frac{1}{l_{c}} \int_{0}^{l_{c}} w_{c}^{\prime 2} d x_{c},
\end{gathered}
$$

where the symbols $m_{b}$ and $m_{c}$ are the mass per unit length of the beam and cable, respectively; $I_{b}$ and $I_{c}$ are the lengths of the beam and cable, respectively; $E_{b} I_{b}$ and $E_{c} A_{c}$ are the bending and axial stiffness of the beam and cable, respectively; $E_{b}, E_{c}$ are the Young's modulus of the material; $I_{b}$ and $A_{c}$ are the moment of area and cross-sectional area, respectively; $N$ is the axial compressive load; $H$ is the initial tension of the cable; $\xi_{b}$ and $\xi_{c}$ are the damping coefficient of the beam and cable, respectively; $\Omega_{b}, \Omega_{c}, P_{b}$, and $P_{c}$ are the frequency and amplitude of the transverse loads, respectively; $w_{b}$ is the beam transverse displacement at location $x_{b}$; and $w_{c}$ is the transverse displacement of the cable at location $x_{c}$. The overdot indicates the differentiation with respect to the time $t$; the prime indicates the differentiation with respect to the coordinate $x$.

The associated geometric and relevant mechanical boundary conditions of the beam and cable are, respectively, written as

$$
\begin{gathered}
w_{b}(0, t)=w_{c}(0, t), \quad w_{b}\left(l_{b}, t\right)=0, \quad w_{c}\left(l_{c}, t\right)=0, \\
w_{b}^{\prime}\left(l_{b}, t\right)=0, \quad w_{b}^{\prime \prime}(0, t)=0, \\
E_{b} I_{b} w_{b}^{\prime \prime \prime}(0, t)=\lambda w_{b}(0, t),
\end{gathered}
$$


where the $\lambda=E_{c} A_{c} / l_{c}$ denotes the out-of-plane supported stiffness of the beam caused by the cable.

For convenience, a set of new variables and parameters are defined as

$$
\begin{gathered}
\tau=\omega t, \quad \bar{x}_{c}=\frac{x_{c}}{l_{c}}, \quad \bar{x}_{b}=\frac{x_{b}}{l_{b}}, \quad \bar{w}_{c}=\frac{w_{c}}{l_{c}}, \\
\bar{w}_{b}=\frac{w_{b}}{l_{b}}, \quad \bar{\xi}_{b}=\frac{\xi_{b}}{m_{b} \omega}, \quad \bar{\xi}_{c}=\frac{\xi_{c}}{m_{c} \omega}, \\
\bar{P}_{b}=\frac{P_{b}}{m_{b} l_{b} \omega^{2}}, \quad \bar{P}_{c}=\frac{P_{c}}{m_{c} l_{c} \omega^{2}}, \quad \rho=\frac{m_{c}}{m_{b}}, \\
\mu=\frac{E_{c} A_{c}}{H}, \quad \chi=\frac{E_{b} I_{b}}{l_{b}^{2} E_{c} A_{c}}, \\
\beta_{b}^{4}=\frac{\omega^{2} m_{b} l_{b}^{4}}{E_{b} I_{b}}, \quad \beta_{c}^{2}=\frac{\omega^{2} m_{c} l_{c}^{2}}{H},
\end{gathered}
$$

where $\omega$ is the natural frequency of the simplified model outplane. In the nondimensional form, (1a)-(3) become

$$
\begin{gathered}
\ddot{w}_{b}+\xi_{b} \dot{w}_{b}+\frac{1}{\beta_{b}^{4}} w_{b}^{\prime \prime \prime \prime}+\frac{\rho w_{b}^{\prime \prime}}{\beta_{c}^{2} \sin (\theta)}+\frac{\rho \mu e(t)}{\beta_{c}^{2} \sin (\theta)} w_{b}^{\prime \prime} \\
=P_{b} \cos \left(\Omega_{b} t\right), \\
\ddot{w}_{c}+\xi_{c} \dot{w}_{c}-\frac{1}{\beta_{c}^{2}} w_{c}^{\prime \prime}-\frac{\mu e(t)}{\beta_{c}^{2}} w_{c}^{\prime \prime}=P_{c} \cos \left(\Omega_{c} t\right), \\
e(t)=\int_{0}^{1} \frac{1}{2} w_{c}^{\prime 2} d x, \\
w_{b}(0, t) \sin (\theta)=w_{c}(0, t), \quad w_{b}(1, t)=0, \\
w_{c}(1, t)=0, \quad w_{b}^{\prime}(1, t)=0, \quad w_{b}^{\prime \prime}(0, t)=0, \\
\chi w_{b}^{\prime \prime \prime}(0, t)=\left(\frac{1}{\mu}+e(t)\right) w_{c}^{\prime}(0) .
\end{gathered}
$$

In this paper, only the first-order modes of the beam and cable are considered. Therefore, based on the research $[15,16]$, the transverse displacements $w_{b}(x, t)$ and $w_{c}(x, t)$ are approximated by the transverse modes of the first order as follows:

$$
\begin{gathered}
w_{b}(x, t)=\psi_{1}(x) p_{1}(t), \\
w_{c}(x, t)=\psi_{1}(x) p_{1}(t) \sin (\theta)+\psi_{2}(x) p_{2}(t),
\end{gathered}
$$

where $\varphi_{1}(x)$ and $\varphi_{2}(x)$ are the mode shapes of the beam and cable, respectively. Both of them have the following form:

$$
\begin{gathered}
\psi_{1}(x)=A_{1} \sin \left(\beta_{b} x\right)+A_{2} \cos \left(\beta_{b} x\right) \\
+A_{3} \sinh \left(\beta_{b} x\right)+A_{4} \cosh \left(\beta_{b} x\right), \\
\psi_{2}(x)=\sin (\pi x) .
\end{gathered}
$$

Using the Galerkin approach, substituting (7a) and (7b) into (5a) and (5b), the nonlinear governing equations of motion with 2-DOFs for the simplified model are obtained as follows:

$$
\begin{aligned}
& \ddot{p}_{1}(t)+\xi_{1} \dot{p}_{1}(t)+a_{1} p_{1}(t)+a_{122} p_{1}(t) p_{2}(t)^{2} \\
& +a_{112} p_{1}(t)^{2} p_{2}(t)+a_{111} p_{1}(t)^{3}=f_{b} \cos \left(\Omega_{b} t\right) \\
& \ddot{p}_{2}(t)+\xi_{2} \dot{p}_{2}(t)+d_{1} \ddot{p}_{1}(t)+d_{2} \dot{p}_{1}(t)+b_{2} p_{2}(t) \\
& +b_{112} p_{1}(t)^{2} p_{2}(t)+b_{122} p_{1}(t) p_{2}(t)^{2}+b_{222} p_{2}(t)^{3} \\
& +b_{1} p_{1}(t)+b_{111} p_{1}(t)^{3}=f_{c} \cos \left(\Omega_{c} t\right) \\
& e(t)=\frac{1}{2} p_{2}(t)^{2} I_{4}+p_{1}(t) p_{2}(t) \sin (\theta) I_{5} \\
& +\frac{1}{2} p_{1}(t)^{2} \sin (\theta)^{2} I_{6}
\end{aligned}
$$

where $f_{b}$ and $f_{c}$ are the amplitude of the harmonic functions and $a_{i}, b_{i}, d_{i}, a_{i j}, b_{i j}, a_{i j k}$, and $b_{i j k}$ are the Galerkin coefficients of the simplified model, respectively. All the coefficients are defined in the Appendix.

3.2. Perturbation Analysis. The multiple scales perturbation method [17] is applied to (9a) and (9b) to obtain an approximation solution of the model. To make the nonlinear terms weak, one can substitute $a_{i j k}, b_{i j k}$, and $c_{i j k}$ with $\varepsilon a_{i j k}, \varepsilon b_{i j k}$, and $\varepsilon c_{i j k}$. Then, (9a) and (9b) can be rewritten as

$$
\begin{aligned}
\ddot{p}_{1}(t) & +\varepsilon \xi_{1} \dot{p}_{1}(t)+\omega_{1}^{2} p_{1}(t)+\varepsilon a_{122} p_{1}(t) p_{2}(t)^{2} \\
& +\varepsilon a_{112} p_{1}(t)^{2} p_{2}(t)+\varepsilon a_{111} p_{1}(t)^{3} \\
& -\varepsilon f_{b} \cos \left(\Omega_{b} t\right)=0, \\
\ddot{p}_{2}(t) & +\varepsilon \xi_{2} \dot{p}_{2}(t)+\varepsilon d_{1} \ddot{p}_{1}(t)+\varepsilon d_{2} \dot{p}_{1}(t)+\omega_{2}^{2} p_{2}(t) \\
& +\varepsilon b_{112} p_{1}(t)^{2} p_{2}(t)+\varepsilon b_{122} p_{1}(t) p_{2}(t)^{2} \\
& +\varepsilon b_{222} p_{2}(t)^{3}+\varepsilon b_{1} p_{1}(t)+\varepsilon b_{111} p_{1}(t)^{3}=0 .
\end{aligned}
$$

Considering the fact there is $1: 1$ internal resonance between the modes of the beam and cable, primary resonance for the beam and autoparametric resonance for the cable, simultaneously, therefore, the resonant relations are represented as

$$
\Omega=\omega_{1}+\varepsilon \sigma_{1}, \quad \omega_{2}=\omega_{1} .
$$

Assuming the first-order approximation solution of (11a) and (11b) in the form

$$
\begin{aligned}
& p_{1}(t)=p_{10}\left(T_{0}, T_{1}\right)+\varepsilon p_{11}\left(T_{0}, T_{1}\right), \\
& p_{2}(t)=p_{20}\left(T_{0}, T_{1}\right)+\varepsilon p_{21}\left(T_{0}, T_{1}\right),
\end{aligned}
$$

the time derivatives become

$$
\begin{gathered}
\frac{d}{d t}=\frac{\partial}{\partial T_{0}} \frac{\partial T_{0}}{\partial t}+\frac{\partial}{\partial T_{1}} \frac{\partial T_{1}}{\partial t}+\cdots=D_{0}+\varepsilon D_{1}+\cdots, \\
\frac{d^{2}}{d t^{2}}=\left(D_{0}+\varepsilon D_{1}+\cdots\right)^{2}=D_{0}^{2}+2 \varepsilon D_{0} D_{1}+\cdots,
\end{gathered}
$$


where $T_{n}=\varepsilon^{n} t(n=0,1)$ are the fast and slow time scales, respectively.

Substituting (13a), (13b), (14a), and (14b) into (11a) and (11b) and equating the powers of $\varepsilon$

$$
\begin{gathered}
D_{1,1}\left(p_{10}\right)+\omega_{1}^{2} p_{10}=0 \\
D_{1,1}\left(p_{20}\right)+\omega_{2}^{2} p_{20}=0 \\
D_{1,1}\left(p_{11}\right)+\omega_{1}^{2} p_{11}+a_{112} p_{10}^{2} p_{20}+2 D_{1,2}\left(p_{10}\right) \\
+\xi_{1} D_{1}\left(p_{10}\right)+a_{122} p_{10} p_{20}^{2}+a_{111} p_{10}^{3} \\
-\cos (\Omega t) f_{b}=0, \\
D_{1,1}\left(p_{21}\right)+\omega_{2}^{2} p_{21}+2 D_{1,2}\left(p_{20}\right)+\xi_{2} D_{1}\left(p_{20}\right) \\
+b_{112} p_{10}^{2} p_{20}+b_{122} p_{10} p_{20}^{2}+b_{111} p_{10}^{3} \\
+d_{1} D_{1,1}\left(p_{10}\right)+d_{2} D_{1}\left(p_{10}\right) \\
+b_{1} p_{10}+b_{222} p_{20}^{3}=0 .
\end{gathered}
$$

The general solution of (15a) and (15b) can be expressed in the form

$$
\begin{aligned}
& p_{10}=A_{1}\left(T_{1}\right) \exp \left(\omega_{1} T_{0}\right)+\bar{A}_{1}\left(T_{1}\right) \exp \left(-\omega_{1} T_{0}\right), \\
& p_{20}=A_{2}\left(T_{1}\right) \exp \left(\omega_{2} T_{0}\right)+\bar{A}_{2}\left(T_{1}\right) \exp \left(-\omega_{2} T_{0}\right),
\end{aligned}
$$

where $A_{1}$ and $A_{2}$ are complex functions and $\overline{A_{1}}$ and $\overline{A_{2}}$ denote complex conjugate terms, respectively.

Substituting (17a) and (17b) and (12), into (16a) and (16b) and setting the coefficients of the secular terms to zero yield the solvability conditions as

$$
\begin{aligned}
& 2 I D_{1}\left(A_{1}\right) \omega_{1}+a_{112} \overline{A_{2}} A_{1}^{2}+a_{122} \overline{A_{1}} A_{2}^{2}+3 a_{111} \overline{A_{1}} A_{1}^{2} \\
& \quad-\frac{1}{2} f_{b} \exp \left(I T_{0} \varepsilon \sigma_{1}\right)+2 a_{112} A_{1} \overline{A_{1}} A_{2} \\
& \quad+I \xi_{1} \omega_{1} A_{1}+2 a_{122} A_{1} A_{2} \overline{A_{2}}=0, \\
& I D_{2} \omega_{1} A_{1}+2 b_{122} A_{1} A_{2} \overline{A_{2}}+2 I D_{2}\left(A_{2}\right) \omega_{1}+b_{112} A_{1}^{2} \overline{A_{2}} \\
& \quad+b_{1} A_{1}+I \xi_{2} \omega_{1} A_{2}+2 b_{112} A_{1} \overline{A_{1}} A_{2} \\
& \quad+b_{122} A_{1} A_{2}^{2}+3 b_{222} A_{2}^{2} A_{2} \\
& \quad+3 b_{111} A_{1}^{2} A_{1}-d_{1} \omega_{1}^{2} A_{1}=0 .
\end{aligned}
$$

Let

$$
A_{k}=\frac{1}{2}\left(x_{k}+i y_{k}\right) \quad(k=1,2) .
$$

Substituting (19) into (18a) and (18b) and then separating the real and imaginary parts, the modulation equations obtained in the Cartesian form are as follows:

$$
\begin{aligned}
\frac{d}{d t} x_{1}(t)= & -\frac{3 y_{1}^{3}+3 y_{1} x_{1}^{2}}{8 \omega_{1}} a_{111} \\
& +\frac{\left(x_{1} x_{2}-3 y_{1} y_{2}\right) \sqrt{x_{1}^{2}+y_{1}^{2}}}{8 \omega_{1}} a_{112} \\
& +\frac{\left(2 x_{1} x_{2} y_{2}-y_{1} x_{2}^{2}-3 y_{1} y_{2}^{2}\right)}{8 \omega_{1}} a_{122} \\
& +\frac{f_{b}+2 y_{1} \sigma_{1} \omega_{1}-x_{1} \xi_{1} \omega_{1}}{2 \omega_{1}}, \\
\frac{d}{d t} y_{1}(t)= & -\frac{3 x_{1}^{3}+3 x_{1} y_{1}^{2}}{8 \omega_{1}} a_{111} \\
& +\frac{\left(y_{1} x_{2}+3 x_{1} y_{2}\right) \sqrt{x_{1}^{2}+y_{1}^{2}}}{8 \omega_{1}} a_{112} \\
& +\frac{\left(2 y_{1} x_{2} y_{2}+x_{1} x_{2}^{2}+3 x_{1} y_{2}^{2}\right)}{8 \omega_{1}} a_{122} \\
& +\frac{-2 x_{1} \sigma_{1} \omega_{1}-y_{1} \xi_{1} \omega_{1}}{2 \omega_{1}},
\end{aligned}
$$

$$
\begin{aligned}
\frac{d}{d t} x_{1}(t)= & -\frac{\left(3 y_{1}^{2}+3 x_{1}^{2}\right) \sqrt{x_{1}^{2}+y_{1}^{2}}}{8 \omega_{1}} b_{111} \\
& -\frac{\left(3 x_{1}^{2} y_{2}+3 y_{1}^{2} y_{2}\right)}{8 \omega_{1}} b_{112} \\
& -\frac{\left(x_{2}^{2}+3 y_{2}^{2}\right) \sqrt{x_{1}^{2}+y_{1}^{2}}}{8 \omega_{1}} b_{122}-\frac{3 x_{2}^{2} y_{2}+3 y_{2}^{3}}{8 \omega_{1}} b_{222} \\
& -\frac{\left(b_{1}-d_{1} \omega_{1}^{2}\right) \sqrt{x_{1}^{2}+y_{1}^{2}}+x_{2} \xi_{2} \omega_{1}-2 y_{2} \sigma_{1} \omega_{1}}{2 \omega_{1}} \\
& -\frac{y_{2}}{x_{1}^{2}+y_{1}^{2}}\left(x_{1} \frac{d}{d t} y_{1}(t)+y_{1} \frac{d}{d t} x_{1}(t)\right),
\end{aligned}
$$

$$
\begin{aligned}
\frac{d}{d t} y_{1}(t)= & \frac{\left(x_{1}^{2} x_{2}+y_{1}^{2} x_{2}\right)}{8 \omega_{1}} b_{112}+\frac{x_{2} y_{2} \sqrt{x_{1}^{2}+y_{1}^{2}}}{4 \omega_{1}} b_{122} \\
& +\frac{3 x_{2} y_{2}^{2}+3 x_{2}^{3}}{8 \omega_{1}} b_{222} \\
& -\frac{d_{2} \omega_{1} \sqrt{x_{1}^{2}+y_{1}^{2}}+y_{2} \xi_{2} \omega_{1}+2 x_{2} \sigma_{1} \omega_{1}}{2 \omega_{1}} \\
& +\frac{x_{2}}{x_{1}^{2}+y_{1}^{2}}\left(x_{1} \frac{d}{d t} y_{1}(t)+y_{1} \frac{d}{d t} x_{1}(t)\right) .
\end{aligned}
$$


It is seen that the (20a), (20b), (20c), and (20d) describe a nonlinear dynamic system, indicating that the transverse vibrations of the cable and tower are nonlinear, even though the beam model considered is linear and neglects the cable's sag effect. The nonlinear terms are only caused by the coupled behaviors between the modes of the beam and cable. It can be demonstrated that the simplified model shows the chaotic motion and period motion with the perturbation force $f_{b}$ changing.

3.3. Numerical Results and Discussion. In fact, there are many internal resonance forms between the modes of a beam and a cable when they act as an overall structure, such as twoto-one, one-to-one, and one-to-two. This study only focuses on the nonlinear vibrations of the simplified model in the one-to-one internal resonance case, taking into consideration the primary resonance to the beam. The parameters of the simplified model are selected as follows: $m_{c}=67.37 \mathrm{~kg} / \mathrm{m}$, $E_{c}=2.10 e 11 \mathrm{~N} / \mathrm{m}^{2}, A_{c}=8.58 e-3 \mathrm{~m}^{2}, l_{c}=152.70 \mathrm{~m}$, $H=609.00 \mathrm{kN}, m_{b}=1.34 e 5 \mathrm{~kg} / \mathrm{m}, l_{b}=76.81 \mathrm{~m}, \theta=30.20^{\circ}$, and $E_{b} I_{b}=8.29 \mathrm{e} 11 \mathrm{~N} \cdot \mathrm{m}^{2}$. Therefore, the nondimension parameters are calculated as follows: $\rho=0.001, \chi=0.068$, $\mu=2959.3, \xi_{1}=0.02, \xi_{2}=0.001$, and $f_{c}=0$. The amplitude of the beam $\left(f_{b}\right)$ is chosen as a controlling parameter. The time histories, phase portraits, and Poincare maps are plotted to analyze the nonlinear dynamical motion of the simplified model. From the numerical simulations, the coupling motion between the beam and cable can be clearly found.

Figure 5 shows the nonlinear behavior of the simplified model at the force amplitude, $f_{b}=0.005$, involving time histories, phase portraits, and Poincare maps. As seen in Figures 5(a) and 5(b), the amplitude history of the beam varies with a particular period, while the cable is disorders and with many subharmonics. However, there are still energy transformation occurred. In order to identify the characteristic of these motions in the time histories, the phase portraits have been calculated. As seen in Figures 5(c) and 5(d), the phase portraits of the beam and cable exhibit periodicity and nonperiodicity, respectively, which are consistent with the description in Figures 5(a) and 5(b). Since the phase portraits cannot provide enough information to determine the onset for chaotic motion, they only are used to distinguish whether the model is periodic or non-periodic. Therefore, the Poincare maps have been further calculated. As seen in Figure 5(e), the Poincare map of the beam exhibits many irregular points, confirming that the motion is chaos. On the other hand, Figure 5(f) exhibits that the return points in the Poincare map form a closed curve. Generally, this shape indicates that this motion is periodic [18]. However, since the motion of the simplified model is coupled, the beam's motion takes on chaos characteristic, and the motion of the cable can be confirmed as chaos motion.

Figure 6 shows the nonlinear behavior of the simplified model at the force amplitude, $f_{b}=0.01$. As shown in Figures 6(a) and 6(b), the varying amplitudes of time history of beam and cable exhibit particular period while the cable has a few subharmonics. The phenomenon of energy transformation between them can be clearly found. As seen in Figures 6(c) and $6(\mathrm{~d})$, the phase portraits of the beam and cable both exhibit periodicity and are further confirmed by Figures 6(e) and $6(f)$. These phenomena indicate that the motions of the beam and cable are both quasi-periodic.

When the forcing amplitude is increased to $f_{b}=0.1$, the nonlinear behavior of the simplified model changes to chaotic motions, as shown in Figure 7 . The Poincare maps given in Figures $7(\mathrm{e})$ and $7(\mathrm{f})$ demonstrate clearly that chaotic motions exist in the simplified model again. It can be observed that the time-histories and phase portraits represented by Figures $7(\mathrm{a}), 7(\mathrm{~b}), 7(\mathrm{c})$, and $7(\mathrm{~d})$ are very similar to that of Figure 6; only the complexity of these graphics increased. On the other hand, compared to Figures $5(\mathrm{a}), 6(\mathrm{a})$, and $7(\mathrm{a})$, the soften phenomenon in the simplified model tends to be more apparent with the force amplitude $\left(f_{b}\right)$ increasing.

\section{Conclusions}

The frequency values of the Bin-Zhou cable-stayed bridge (BZB) influenced by the cable vibration have been investigated by two FE models in this study. One is the OECS model in which one single element per cable stay is used and the other is MECS model, where multi-elements per cable stay are used. The nonlinear behaviors of the cable vibration of $\mathrm{BZB}$ have also been examined by a simplified model, where the tower is simplified as a beam. The motions of the simplified model are utilized by Galerkin's method to truncate a two DOFs nonlinear coupled model. Based on above numerical experiments, some conclusions are summarized as follows.

(1) The local vibration of the cables only has a small impact on the frequency values of the BZB but increase for the deck and decrease for the towers.

(2) The results from the modal analysis also show that the modes of the towers are main component of the BZB in the first 10 modes, and most of them are the lateral vibrations. Compared to the OESC model, the MECS model not only offers global modes of the bridge, but also exhibits the local vibration of the cables.

(3) The results from the simplified model analysis show that the coupled system exhibits quasi-periodic and chaotic motion with the forcing amplitude changing, even though the beam model is linear and the cable model neglects the cable's sag effect. The simplified model also exhibits soften behavior with the forcing amplitude increasing.

(4) The energy transform can be found due to the $1: 1$ internal resonant between the modes of the beam and cable. 


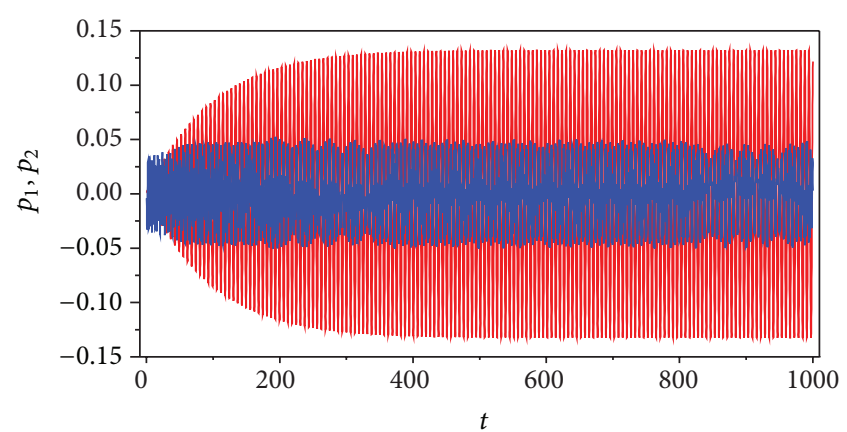

(a)

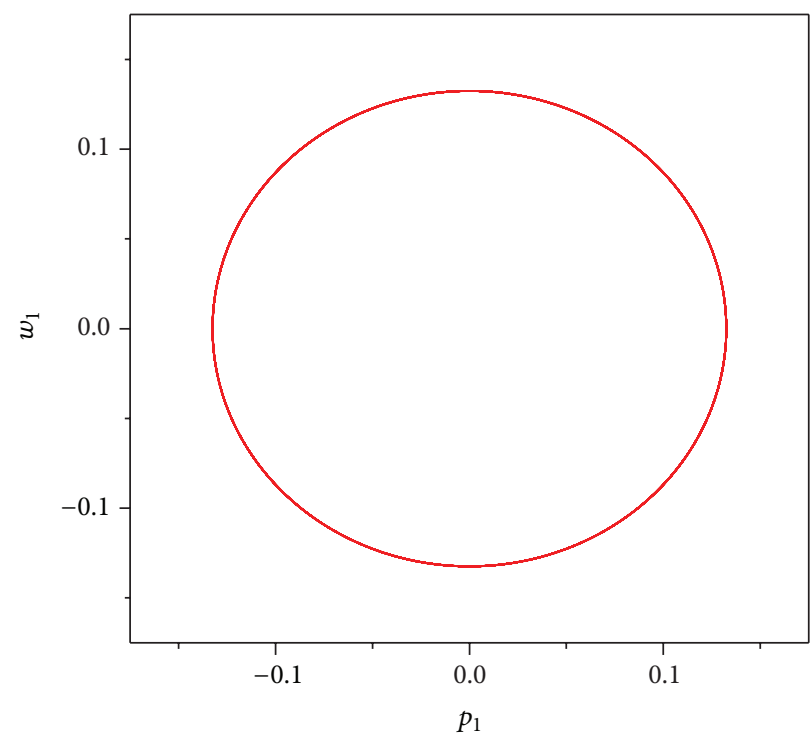

(c)

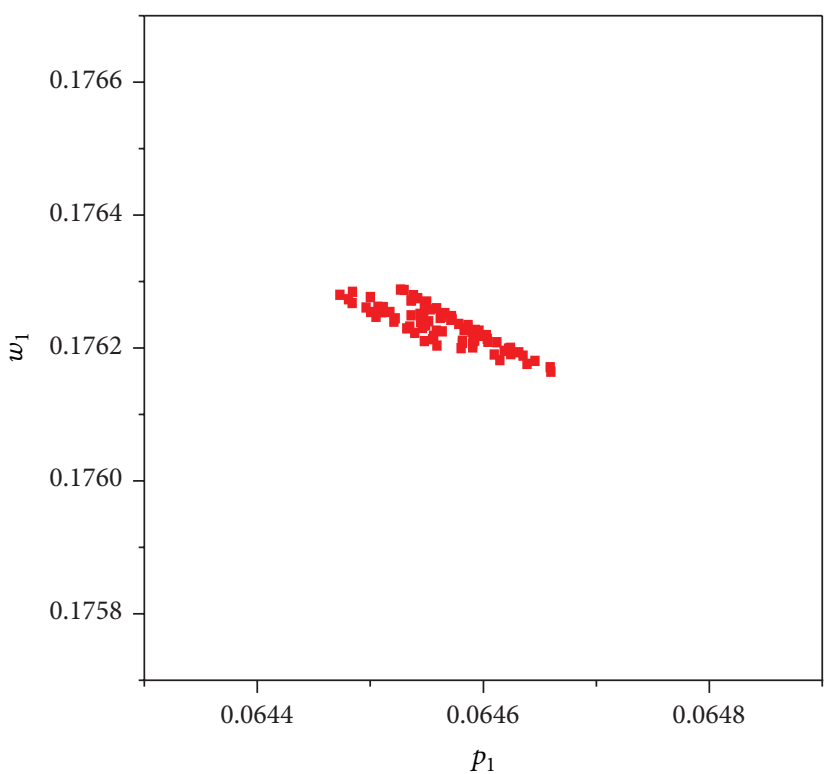

(e)

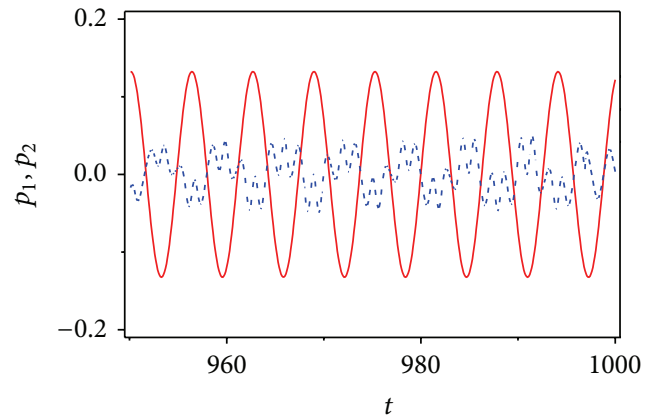

(b)

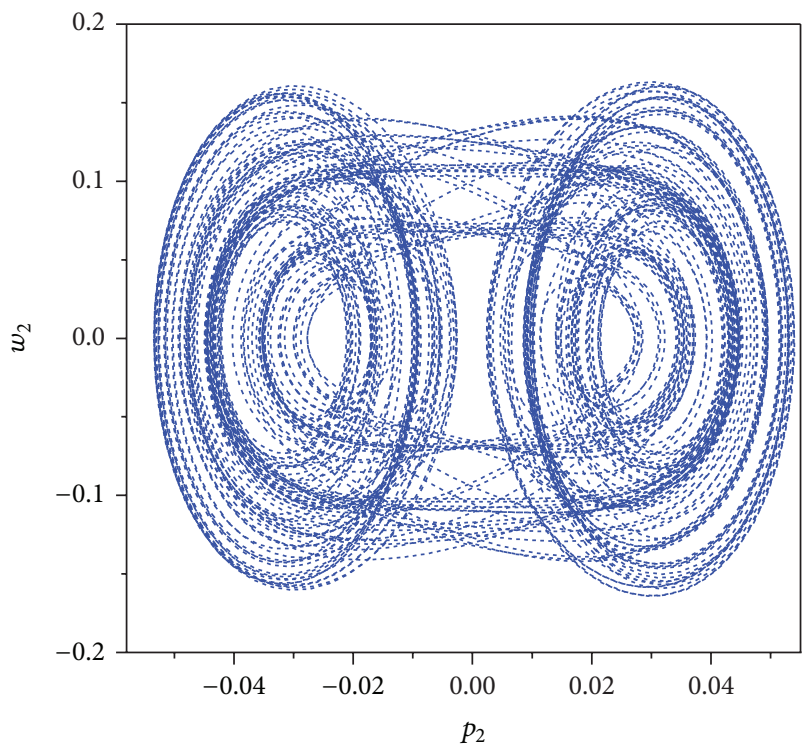

(d)

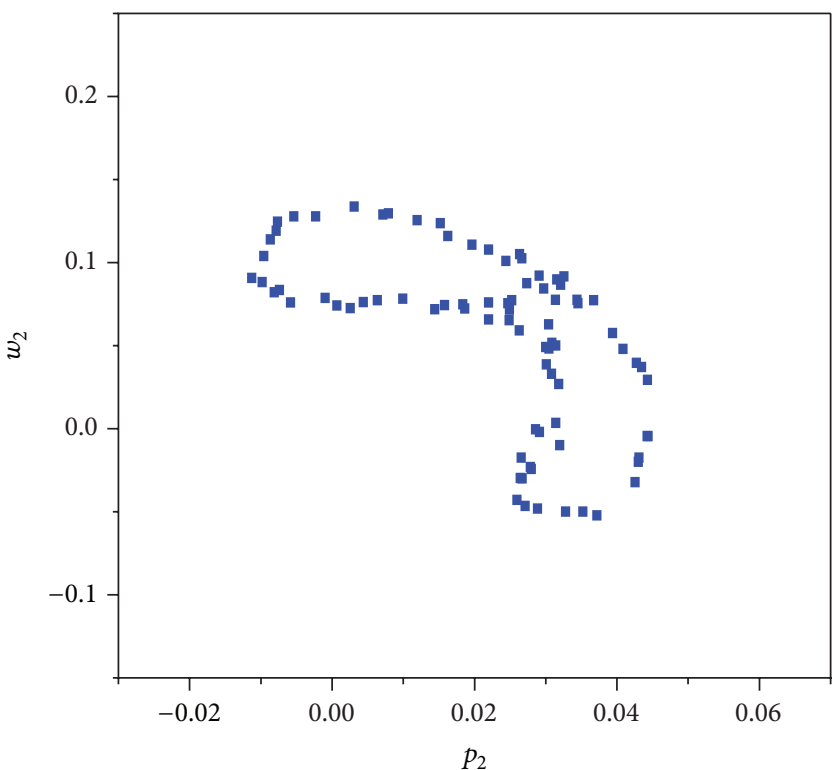

(f)

Figure 5: Nonlinear response of the simplified model when the $f_{b}=0.005$ (98.3 KN): (a) Time history; (b) Local magnification of (a); (c) Phase portrait of the beam; (d) Phase portrait of the cable; (e) Poincare map of the beam; (f) Poincare map of the cable; (continued line beam, dashed line cable; $\left.p_{10}=0.001, p_{20}=0.032, D p_{10}=0.001, D p_{20}=-0.01\right)$. 


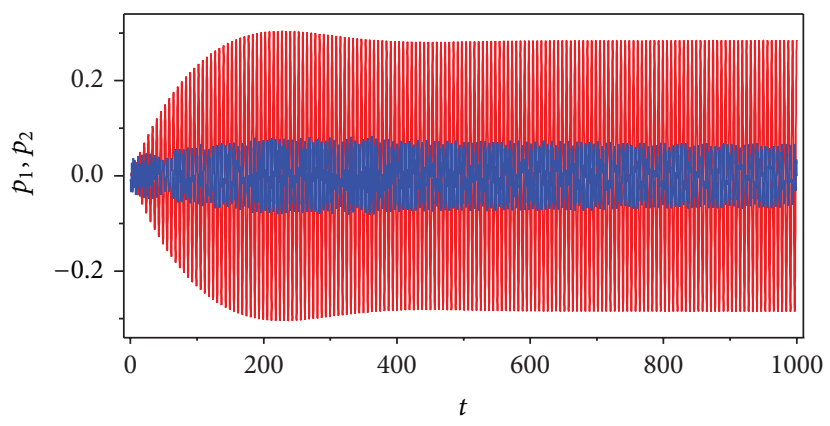

(a)

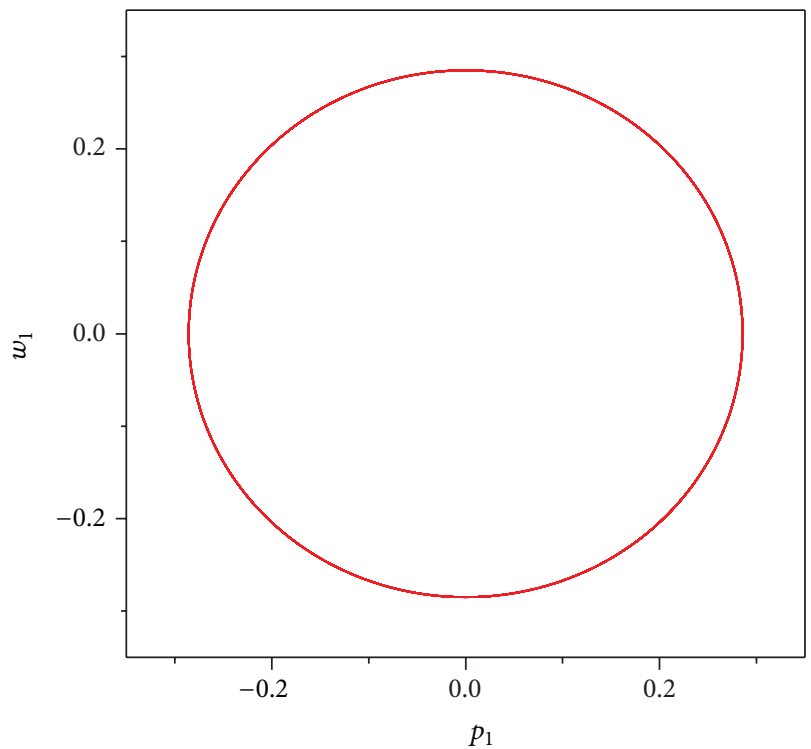

(c)

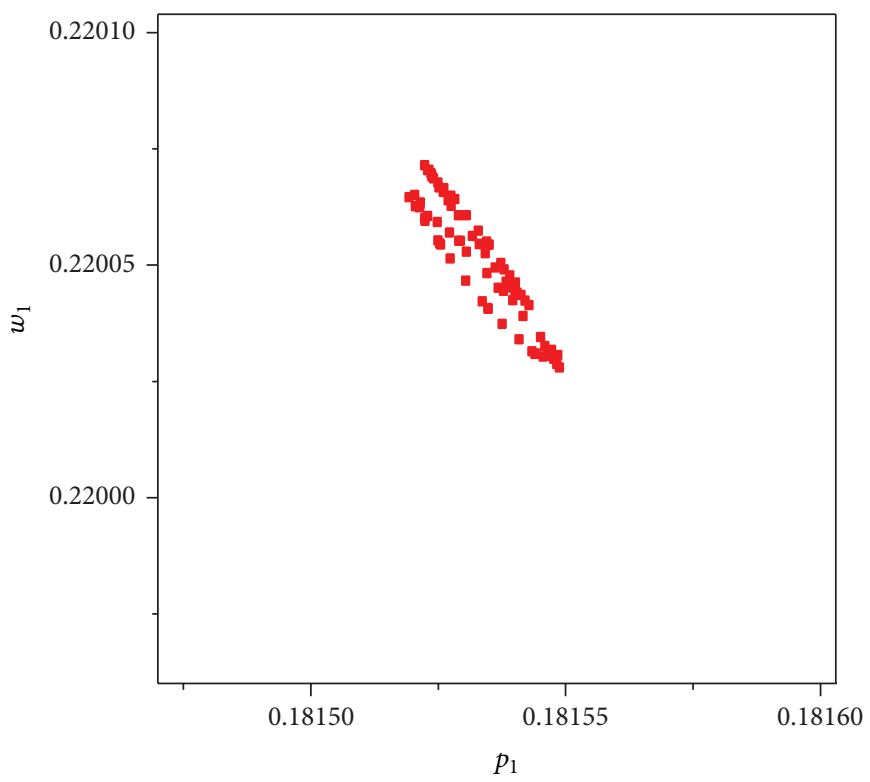

(e)

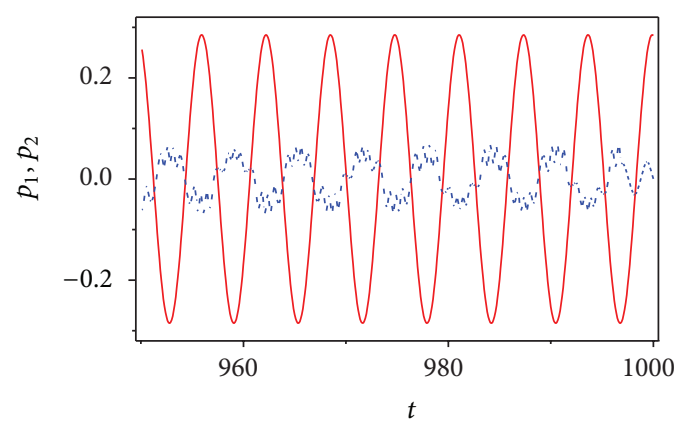

(b)

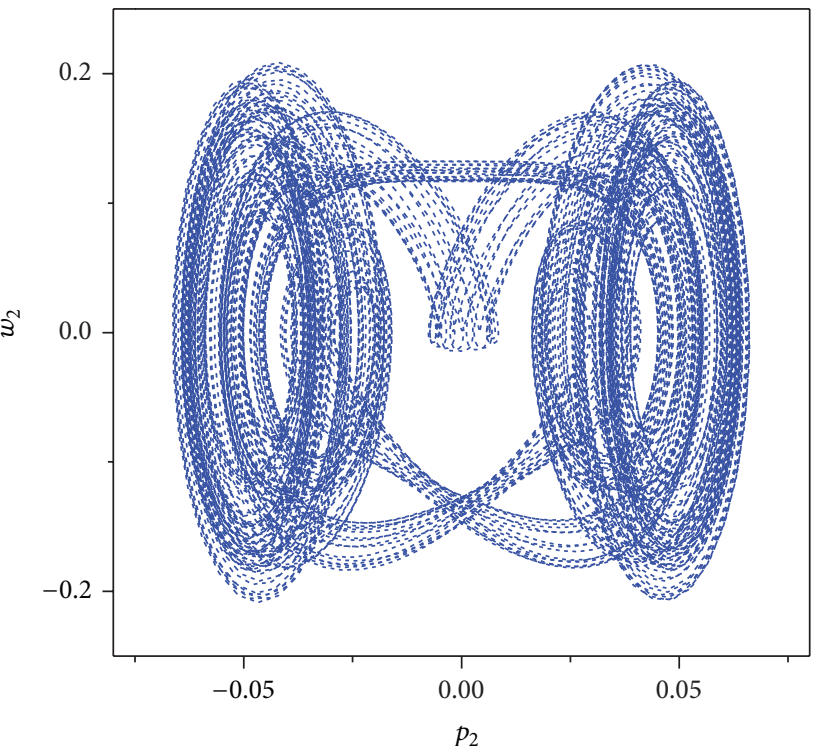

(d)

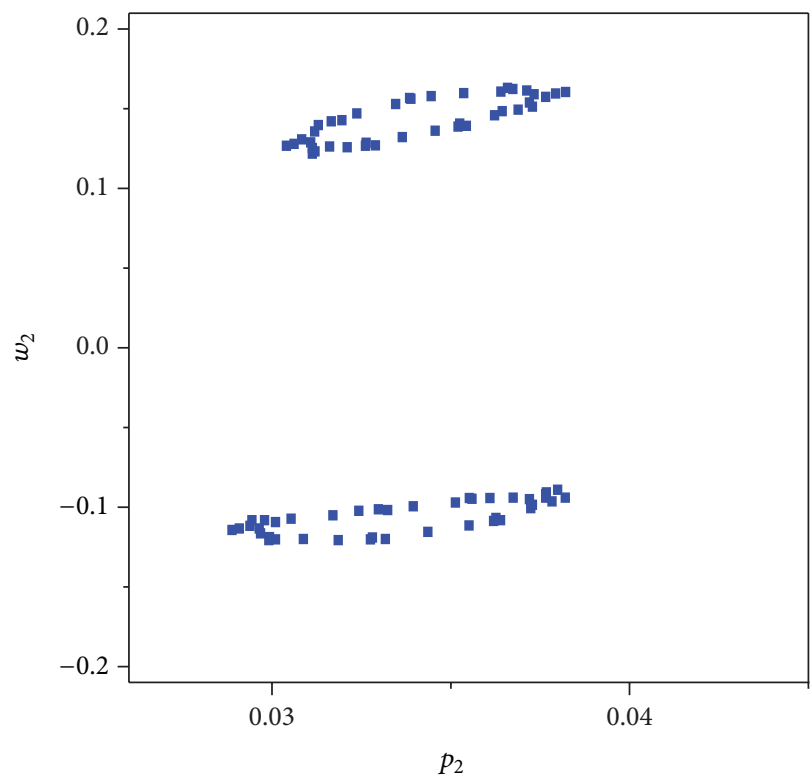

(f)

Figure 6: Nonlinear response of the simplified model when the $f_{b}=0.01$ (197.46 kN): (a) Time history; (b) Local magnification of (a); (c) Phase portrait of the beam; (d) Phase portrait of the cable; (e) Poincare map of the beam; (f) Poincare map of the cable; (continued line beam, dashed line cable; $p_{10}=0.001, p_{20}=0.032, D p_{10}=0.001, D p_{20}=-0.01$ ). 


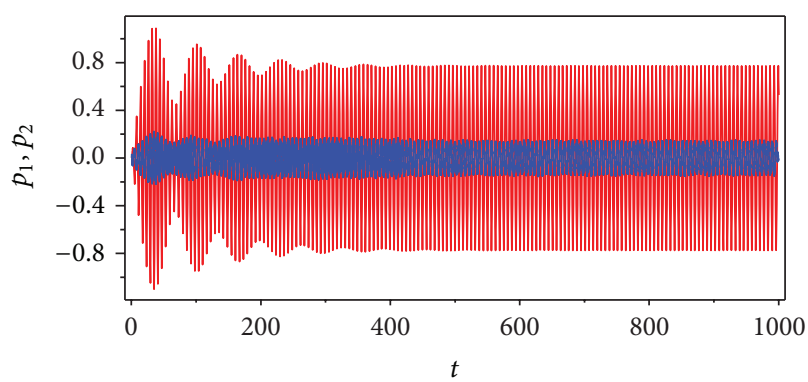

(a)

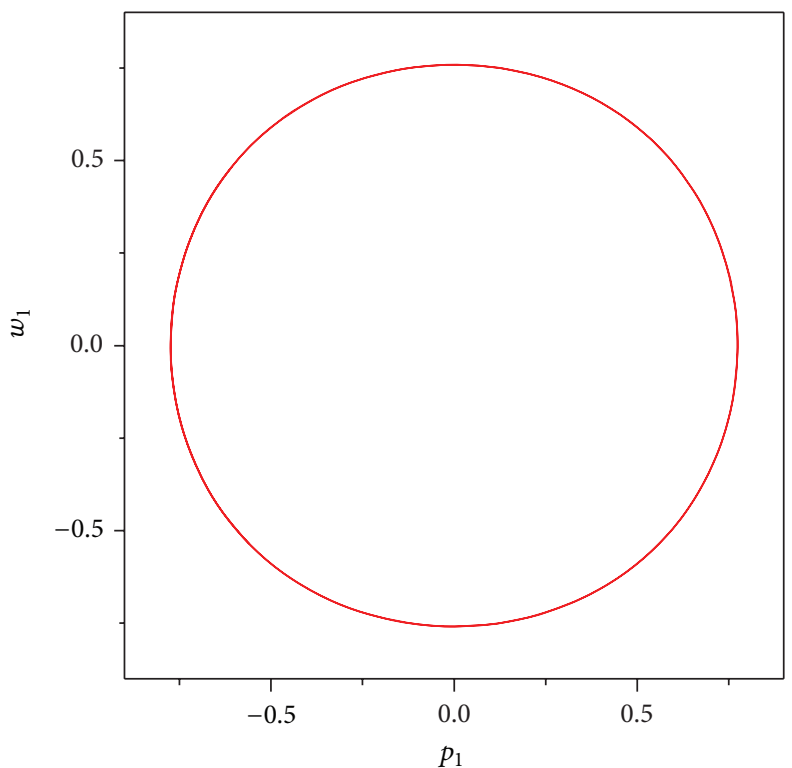

(c)

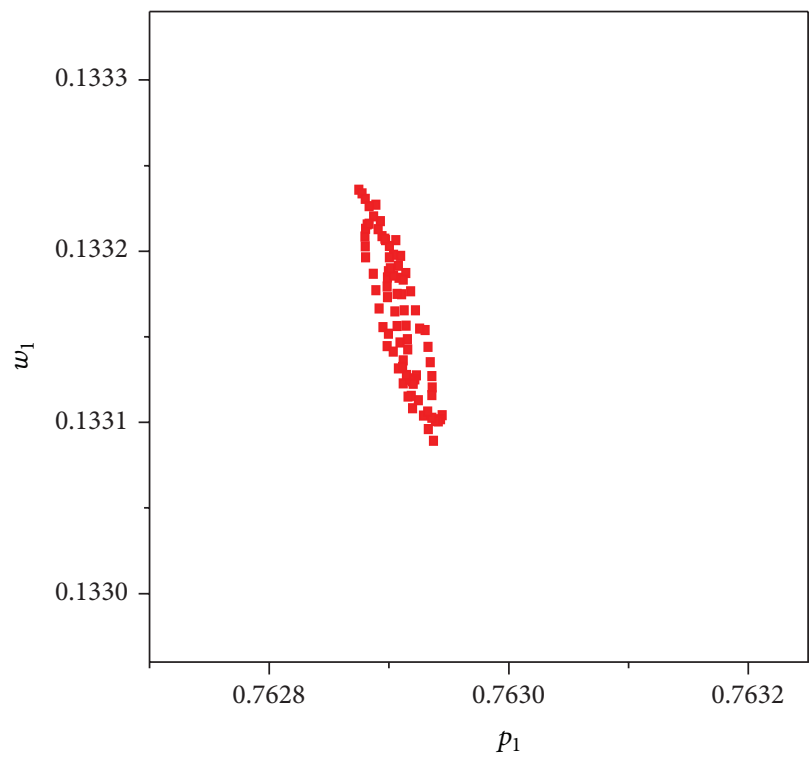

(e)

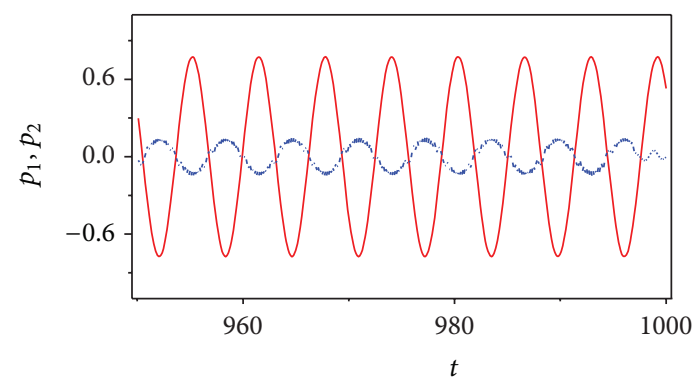

(b)

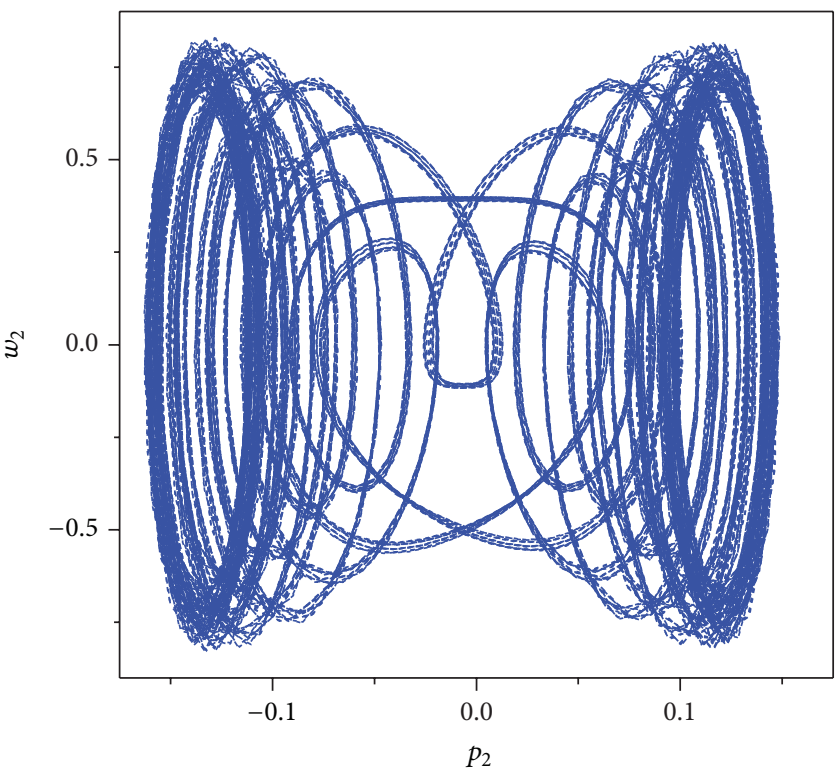

(d)

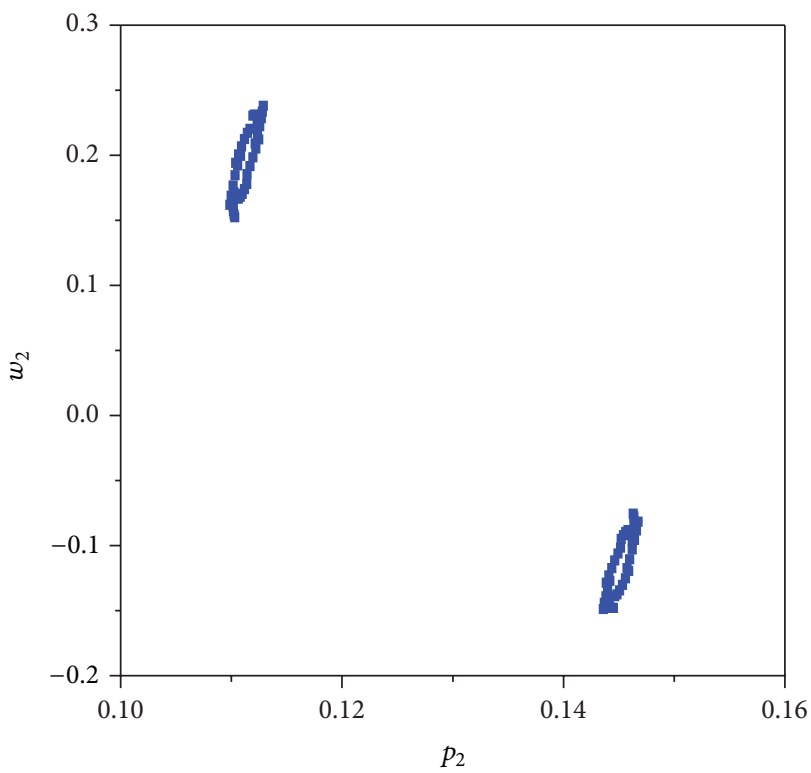

(f)

Figure 7: Nonlinear response of the simplified model when the $f_{b}=0.1$ (1974.58 kN): (a) Time history; (b) Local magnification of (a); (c) Phase portrait of the beam; (d) Phase portrait of the cable; (e) Poincare map of the beam; (f) Poincare map of the cable; (continued line beam, dashed line cable; $p_{10}=0.001, p_{20}=0.032, D p_{10}=0.001, D p_{20}=-0.01$ ). 


\section{Appendix}

One has

$$
\begin{aligned}
& I_{1}=\int_{0}^{1} D\left(\psi_{2}\right)(x)^{2} d x \\
& I_{2}=\int_{0}^{1} D\left(\psi_{2}\right)(x) D\left(\psi_{1}\right)(x) d x \\
& I_{3}=\int_{0}^{1} D\left(\psi_{1}\right)(x)^{2} d x, \quad I_{4}=\int_{0}^{1} \psi_{1}(x)^{2} d x, \\
& I_{5}=\int_{0}^{1} \psi_{1}(x) D^{(4)}\left(\psi_{1}\right)(x) d x, \\
& I_{6}=\int_{0}^{1} \psi_{1}(x) D^{(2)}\left(\psi_{1}\right)(x) d x, \\
& I_{7}=\int_{0}^{1} \psi_{1}(x) P_{w b}(x) d x, \quad I_{8}=\int_{0}^{1} \psi_{2}(x)^{2} d x, \\
& I_{9}=\int_{0}^{1} \psi_{1}(x) \psi_{2}(x) d x \\
& I_{10}=\int_{0}^{1} \psi_{2}(x) D^{(2)}\left(\psi_{2}\right)(x) d x \\
& I_{11}=\int_{0}^{1} \psi_{2}(x) D^{(2)}\left(\psi_{1}\right)(x) d x \text {, } \\
& I_{12}=\int_{0}^{1} \psi_{2}(x) P_{w c}(x) d x, \\
& a_{111}=\frac{1}{2} \frac{\rho \mu \sin (\theta) I_{6} I_{3}}{\beta_{c}^{2} I_{4}}, \quad a_{112}=\frac{\rho \mu I_{6} I_{2}}{\beta_{c}^{2} I_{4}} \text {, } \\
& a_{122}=\frac{1}{2} \frac{\rho \mu I_{6} I_{1}}{\beta_{c}^{2} \sin (\theta) I_{4}}, \\
& a_{1}=\frac{I_{5}}{\beta_{b}^{4} I_{4}}+\frac{\rho I_{6}}{\beta_{c}^{2} \sin (\theta) I_{4}}, \quad f_{b}=\frac{I_{7}}{I_{4}}, \\
& b_{222}=-\frac{1}{2} \frac{\mu I_{10} I_{1}}{I_{8} \beta_{c}^{2}} \\
& b_{122}=-\frac{\mu \sin (\theta) I_{10} I_{2}}{I_{8} \beta_{c}^{2}}-\frac{1}{2} \frac{\mu \sin (\theta) I_{11} I_{1}}{I_{8} \beta_{c}^{2}} \text {, } \\
& b_{111}=-\frac{1}{2} \frac{\mu \sin (\theta)^{3} I_{11} I_{3}}{I_{8} \beta_{c}^{2}} \text {, } \\
& b_{112}=-\frac{1}{2} \frac{\mu \sin (\theta)^{2} I_{10} I_{3}}{I_{8} \beta_{c}^{2}}-\frac{\mu \sin (\theta)^{2} I_{11} I_{2}}{I_{8} \beta_{c}^{2}} \text {, } \\
& b_{2}=-\frac{I_{10}}{I_{8} \beta_{c}^{2}}, \quad b_{1}=-\frac{\sin (\theta) I_{11}}{I_{8} \beta_{c}^{2}}, \\
& d_{1}=\frac{\sin (\theta) I_{9}}{I_{8}}, \quad d_{2}=\frac{\xi_{2} \sin (\theta) I_{9}}{I_{8}}, \\
& f_{c}=\frac{I_{12}}{I_{8}}
\end{aligned}
$$

\section{Conflict of Interests}

The authors declare that there is no conflict of interests regarding the publication of this paper.

\section{Acknowledgments}

The present study was sponsored by National Natural Science Foundation of China (Grants nos. 51308322, 51078119), China Postdoctoral Science Foundation (Grant no. 2013M541387, 2013M530049), Fund of State Key Laboratory of Bridge Engineering Structural Dynamics (Grant no. 201301), and Fund of National Engineering and Research Center for Highways in Mountain Area (Grant no. gsgzj-2013-03).

\section{References}

[1] Y. Q. Ni, J. Y. Wang, and L. C. Lo, "Influence of stabilizing cables on seismic response of a multispan cable-stayed bridge," Computer-Aided Civil and Infrastructure Engineering, vol. 20, no. 2, pp. 142-153, 2005.

[2] G. J. He, Z. Q. Zou, Y. Q. Ni, and J. M. Ko, "Seismic response analysis of multi-span cable-stayed bridge," Key Engineering Materials, vol. 400-402, pp. 737-742, 2009.

[3] J. L. Liu, Study of control for seismic damage modes of cablestayed bridge with multi-tower [Ph.D. thesis], Harbin Institute of Technology, Harbin, China, 2009, (Chinese).

[4] Y. Okamoto and S. Nakamura, "Static and seismic studies on steel/concrete hybrid towers for multi-span cable-stayed bridges," Journal of Constructional Steel Research, vol. 67, no. 2, pp. 203-210, 2011.

[5] Y. Fujino, P. Warnitchai, and B. M. Pacheco, "An experimental and analytical study of autoparametric resonance in a $3 \mathrm{DOF}$ model of cable-stayed-beam," Nonlinear Dynamics, vol. 4, no. 2, pp. 111-138, 1993.

[6] Y. Xia and Y. Fujino, "Auto-parametric vibration of a cablestayed-beam structure under random excitation," Journal of Engineering Mechanics, vol. 132, no. 3, pp. 279-286, 2006.

[7] Y. Xia, Q.-X. Wu, Y.-L. Xu, Y. Fujino, and X.-Q. Zhou, "Verification of a cable element for cable parametric vibration of onecable-beam system subject to harmonic excitation and random excitation," Advances in Structural Engineering, vol. 14, no. 3, pp. 589-595, 2011.

[8] E. Caetano, A. Cunha, and C. A. Taylor, "Investigation of dynamic cable-deck interaction in a physical model of a cablestayed bridge. Part I: modal analysis," Earthquake Engineering and Structural Dynamics, vol. 29, no. 4, pp. 481-498, 2000.

[9] E. Caetano, A. Cunha, and C. A. Taylor, "Investigation of dynamic cable-deck interaction in a physical model of a cablestayed bridge. Part II: seismic response," Earthquake Engineering and Structural Dynamics, vol. 29, no. 4, pp. 499-521, 2000.

[10] C. T. Georgakis and C. A. Taylor, "Nonlinear dynamics of cable stays. Part 1: sinusoidal cable support excitation," Journal of Sound and Vibration, vol. 281, no. 3-5, pp. 537-564, 2005.

[11] C. T. Georgakis and C. A. Taylor, "Nonlinear dynamics of cable stays. Part 2: stochastic cable support excitation," Journal of Sound and Vibration, vol. 281, no. 3-5, pp. 565-591, 2005.

[12] E. Caetano, A. Cunha, V. Gattulli, and M. Lepidi, "Cable-deck dynamic interactions at the International Guadiana Bridge: onsite measurements and finite element modelling," Structural Control and Health Monitoring, vol. 15, no. 3, pp. 237-264, 2008. 
[13] Y. Q. Ni, H. F. Zhou, K. C. Chan, and J. M. Ko, "Modal flexibility analysis of cable-stayed Ting Kau bridge for damage identification," Computer-Aided Civil and Infrastructure Engineering, vol. 23, no. 3, pp. 223-236, 2008.

[14] P. H. Wang, M. Y. Liu, Y. T. Huang, and L. C. Lin, "Influence of lateral motion of cable stays on cable-stayed bridges," Structural Engineering and Mechanics, vol. 34, no. 6, pp. 719-738, 2010.

[15] G. Cheng and J. W. Zu, "Dynamic analysis of an optical fiber coupler in telecommunications," Journal of Sound and Vibration, vol. 268, no. 1, pp. 15-31, 2003.

[16] Q. Wu, K. Takahashi, T. Okabayashi, and S. Nakamura, "Response characteristics of local vibrations in stay cables on an existing cable-stayed bridge," Journal of Sound and Vibration, vol. 261, no. 3, pp. 403-420, 2003.

[17] A. H. Nayfeh and D. T. Mook, Nonlinear Oscillations, John Wiley \& Sons, New York, NY, USA, 1979.

[18] C.-W. Chang-Jian and C.-K. Chen, "Nonlinear analysis of a rub-impact rotor supported by turbulent couple stress fluid film journal bearings under quadratic damping," Nonlinear Dynamics, vol. 56, no. 3, pp. 297-314, 2009. 


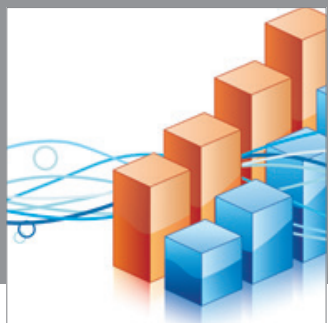

Advances in

Operations Research

mansans

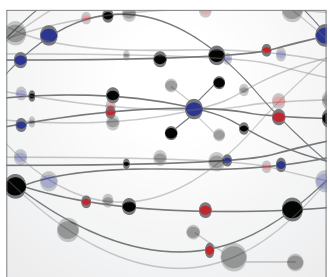

The Scientific World Journal
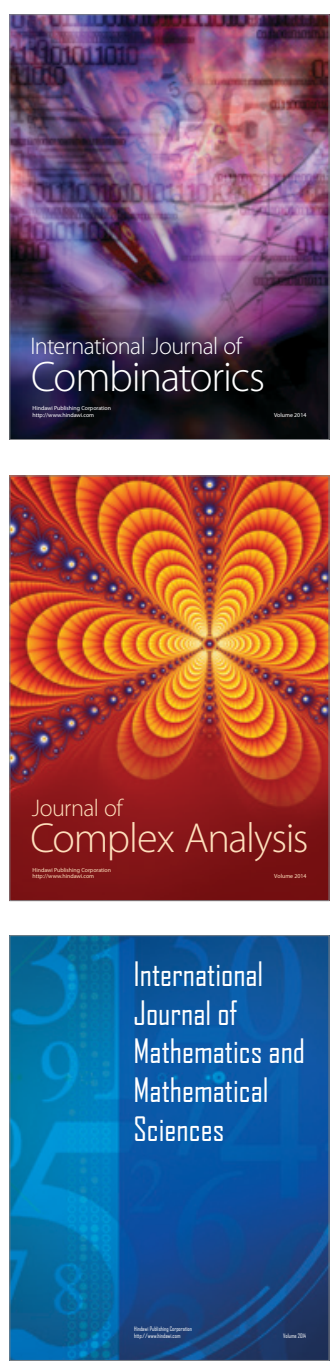
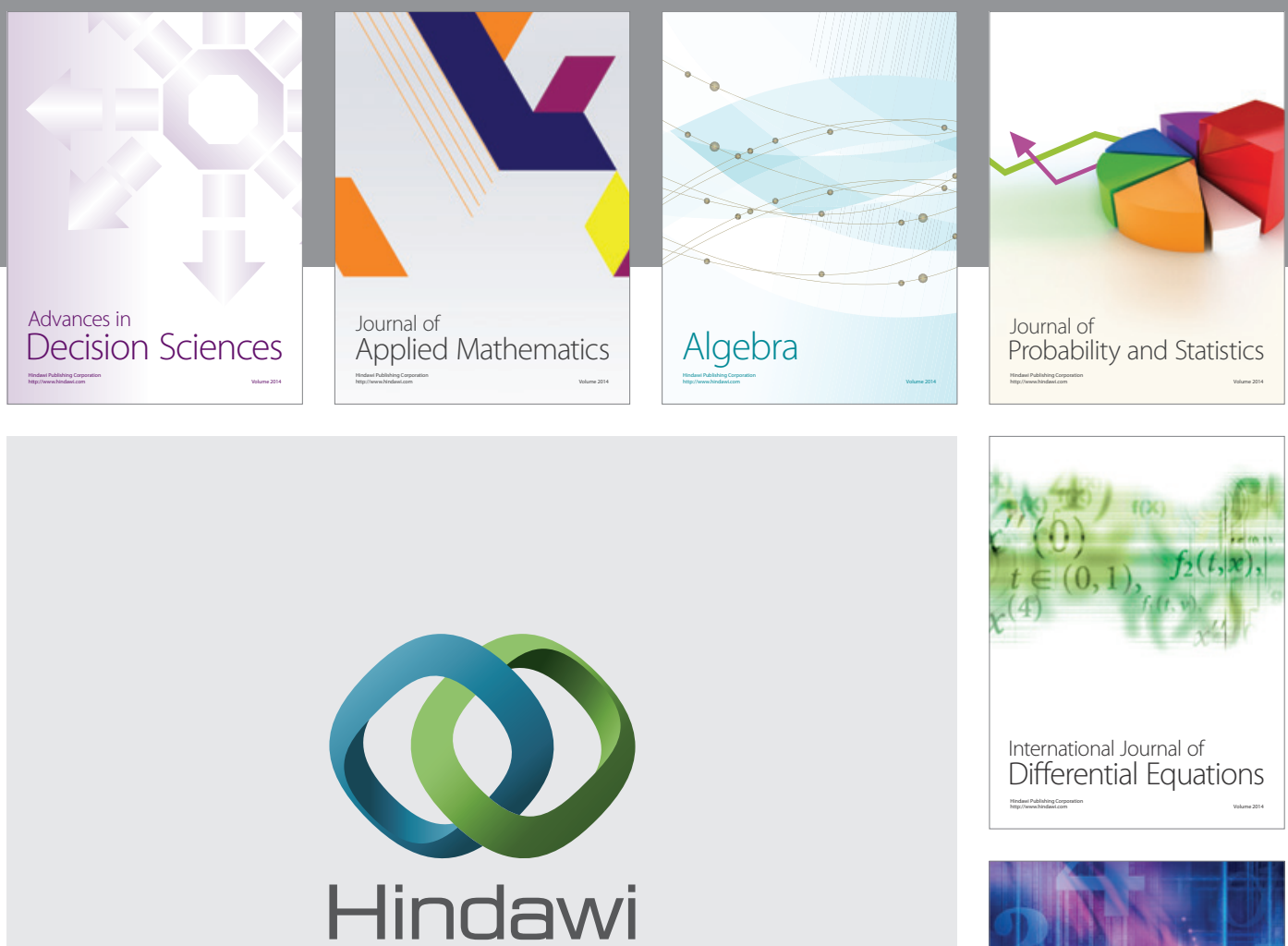

Submit your manuscripts at http://www.hindawi.com
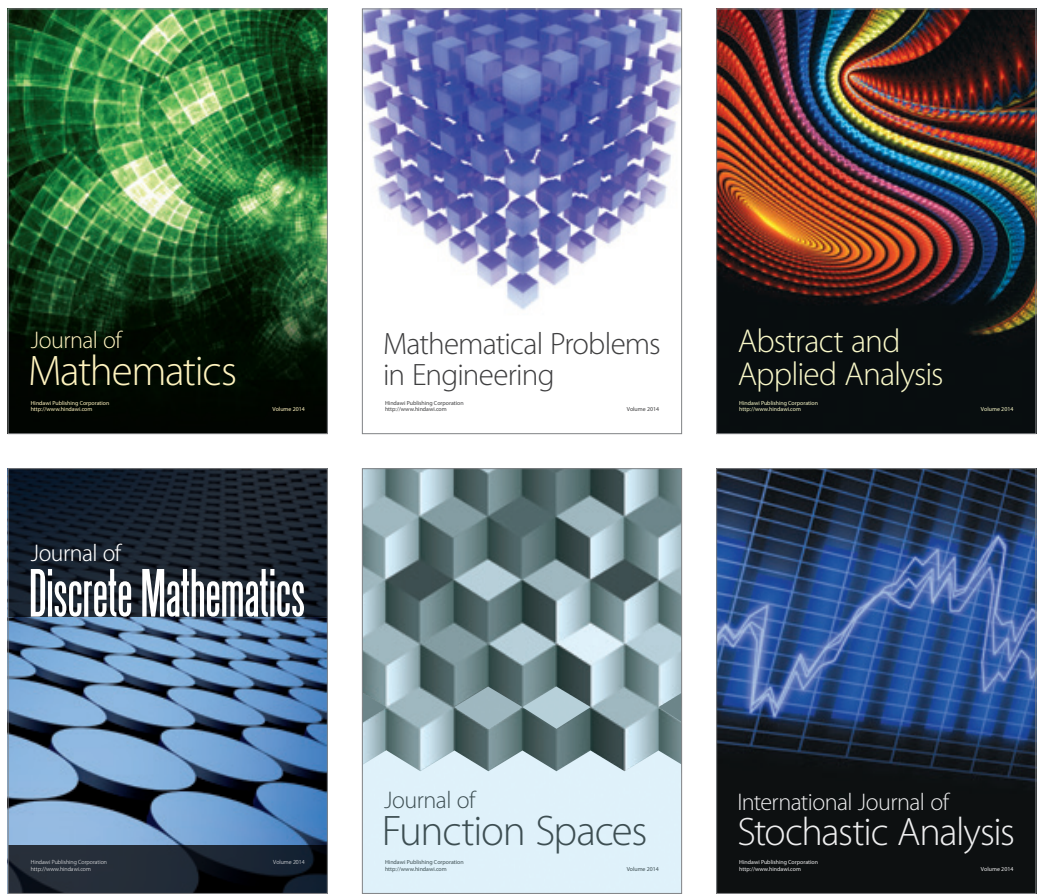

Journal of

Function Spaces

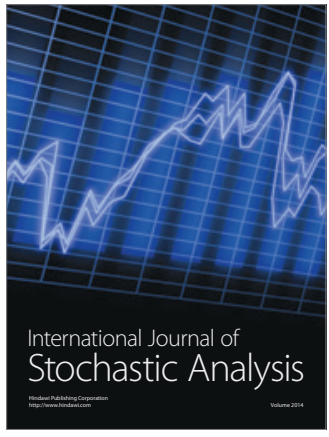

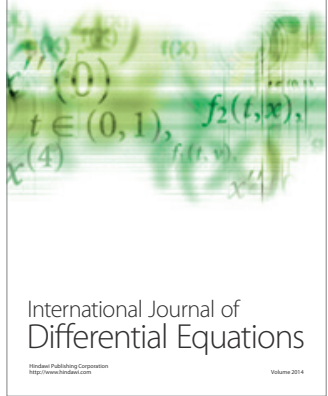
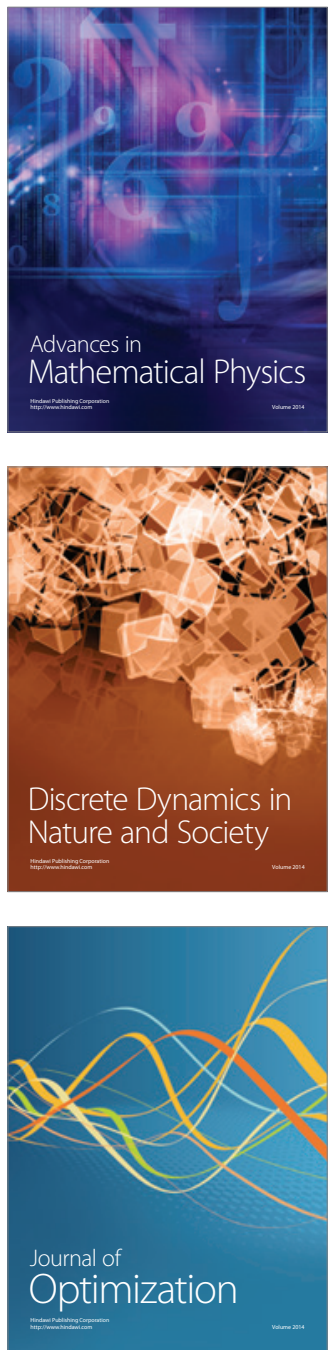